\title{
A New Charging Protocol for Blast Furnaces
}

\author{
N. S. Polyakov, S. B. Bloshkin, and R. E. Beseda \\ OAO Chelyabinskii Metallurgicheskii Kombinat, Chelyabinsk, Russia
}

\begin{abstract}
After tests at OAO Chelyabinskii Metallurgicheskii Kombinat, a new protocol has been introduced for blast-furnace charging. The proposed cycle consists of several mixed deliveries (ore + coke) and finally the delivery of several charging ladles with a single type of coke. This protocol has now been introduced at all three blast furnaces, with decrease in coke consumption and increase in furnace productivity.
\end{abstract}

DOI: $10.3103 / \mathrm{S} 096709121303008 \mathrm{X}$

Blast-furnace smelting is a continuous metallurgical process based on the counterflow principle, in which thermal and mass transfer is very economical.

High blast-furnace performance depends on the maintenance of uniform conditions: in general terms, stable gas-dynamic conditions and a normal thermal state. The maintenance of uniform conditions is the primary goal of blast-furnace control.

High performance requires a rational distribution of batch and gases over the furnace circumference and radius. That ensures high productivity with minimum coke consumption. The required distribution of batch and gas fluxes over the furnace radius is ensured by calculating the optimal charging program for the specific furnace and the chemical and granulometric composition of the batch materials.

At OAO Chelyabinskii Metallurgicheskii Kombinat, a new protocol for blast-furnace charging has been tested and introduced. The plant has three working blast furnaces, whose useful volume is 2038, 1719, and $1386 \mathrm{~m}^{3}$, respectively. The furnaces are equipped with double-cone charging systems, which somewhat restrict the selection of an optimal batch distribution over the charge hole, in contrast to up-to-date systems of trough and rotor type.

To improve the distribution of the gas fluxes - and hence the reducing properties of the gas, the coke consumption, and the furnace productivity - a charging protocol with layering of the coke has been tested. The proposed cycle consists of several mixed deliveries (ore + coke) and finally the delivery of several charging ladles with a single type of coke:

\section{OOOCC \\ 2 OOOCCC \\ $1 \mathrm{CCCCC}$}

Regular charging protocols do not fully utilize the reducing properties of the gas on account of its distribution over the furnace radius, and the presence of the coke layer has a balancing effect, which improves the furnace's operational efficiency.

The new charging protocol has been tested at blast furnace 4 (useful volume $1386 \mathrm{~m}^{3}$ ), with positive results. Specifically, the coke consumption is reduced by $2 \mathrm{~kg} / \mathrm{t}$ : to 446 from $448 \mathrm{~kg} / \mathrm{t}$ for the regular charging protocol. Tests show that the results depend on the quality of the charge. With deterioration in coke strength $M_{25}$ and $M_{10}$ and increase in the sinter's content of fines, furnace operation becomes unstable, and the productivity falls.

In August 2012, analogous charging protocols were introduced at the other two furnaces, with improvement in coke consumption to $441 \mathrm{~kg} / \mathrm{t}$. Currently, all three furnaces operate with the new charging protocol, and we have noted lower coke consumption and greater furnace productivity.

\section{CONCLUSIONS}

The conditions of ore and coke delivery ensuring the best batch and gas distribution over the furnace radius are established by trial and error, with attendant expenditures of time and the potential for loss of furnace performance. The use of a charging protocol with layering of the coke (in conditions with stable coke and ore quality) improves furnace productivity and may be recommended for other blast furnaces with a doublecone charging system. 